
\title{
$\begin{array}{ll}\text { Research Square } & \begin{array}{l}\text { Preprints are preliminary reports that have not undergone peer review. } \\ \text { They should not be considered conclusive, used to inform clinical practice, } \\ \text { or referenced by the media as validated information. }\end{array}\end{array}$
}

\section{Sustained Response To Onabotulinumtoxin A In Patients With Chronic Migraine: Real-Life Data}

\author{
Raffaele Ornello \\ University of L'Aquila \\ Simona Guerzoni \\ Universita degli Studi di Modena e Reggio Emilia \\ Carlo Baraldi \\ Universita degli Studi di Modena e Reggio Emilia \\ Luana Evangelista \\ University of L'Aquila \\ Ilaria Frattale \\ University of L'Aquila \\ Carmine Marini \\ University of L'Aquila \\ Cindy Tiseo \\ University of L'Aquila \\ Francesca Pistoia \\ University of L'Aquila
}

Simona Sacco ( $\nabla$ simona.sacco@univaq.it)

University of L'Aquila https://orcid.org/0000-0003-0651-1939

\section{Research article}

Keywords: headache, migraine, botulinum toxin, response, prevention, open-label study

Posted Date: March 24th, 2020

DOI: https://doi.org/10.21203/rs.3.rs-18479/v1

License: (c) (i) This work is licensed under a Creative Commons Attribution 4.0 International License. Read Full License

Version of Record: A version of this preprint was published at The Journal of Headache and Pain on April 25th, 2020. See the published version at https://doi.org/10.1186/s10194-020-01113-6. 


\section{Abstract}

Background

Treatment with onabotulinumtoxin A (BT-A) is safe and effective for chronic migraine (CM). Several studies assessed possible predictors of response to treatment with BT-A, but there is little knowledge on the frequency and predictors of sustained response. The aim of this study was to evaluate sustained response to $\mathrm{BT}-\mathrm{A}$ in patients with $\mathrm{CM}$.

Main body

In this prospective open-label study, 115 patients with CM and treated with BT-A were consecutively enrolled in two Italian headache centers and followed up for 15 months. Anytime responders were defined as those patients who achieved a $\geq 50 \%$ reduction in headache days during any three-month treatment cycle compared with the three months prior to initiation of BT-A treatment. Sustained responders were defined as those who achieved a $\geq 50 \%$ reduction in headache days within the third treatment cycle and maintained response until the end of follow-up. Non-responders were defined as those patients who never achieved $\mathrm{a} \geq 50 \%$ reduction in headache days during the follow-up. Headache characteristics prior to BT-A treatment were assessed in order to evaluate their ability in predicting treatment response. The 115 enrolled patients ( $84.3 \%$ female; median age 50 years) had a median migraine duration of 30 years (interquartile range 22-38). At the end of follow-up, 66 patients (57.4\%) were classified as anytime responders. Among the 51 patients who achieved a clinical response within the third month of treatment, 33 (64.7\%) were sustained responders. Patients with sustained response had a lower CM duration (median 31 vs 65 months; $\mathrm{P}=0.030$ ) and a lower number of headache days (median 25 vs 30; $\mathrm{P}=0.013$ ) at baseline compared with non-responders.

Conclusions

About two thirds of patients who gain $\geq 50 \%$ response to BT-A within the third cycle of treatment maintain this positive response over time. More recent onset of $\mathrm{CM}$ and more headache-free days at baseline are associated with sustained response. We suggest not to delay preventive treatment of CM with BT-A, in order to increase the likelihood to achieve sustained clinical response.

\section{Background}

Chronic migraine (CM) is defined as the occurrence of $\geq 15$ monthly headache days, of which $\geq 8$ monthly migraine days, for $\geq 3$ months [1]. The abovementioned definition remains valid even if some authors have recently proposed to consider $\geq 8$ monthly migraine days for $\geq 3$ months as sufficient to diagnose $\mathrm{CM}$ [2]. CM has a prevalence in the general population of about 2\% [3] and imposes a significant burden on the patients in terms of social exclusion, isolation, anxiety, and depression, significantly lowering their quality of life [4, 5]. Onabotulinumtoxin A (BT-A) is a safe and effective preventive treatment for CM, as shown in the Phase 3 Research Evaluating Migraine Prophylaxis Therapy (PREEMPT) trials [7-11]. Several real-life studies confirmed its safety and efficacy in clinical practice [12-21] and showed that a shorter disease duration, some characteristics of headache (ocular, imploding), allodynia, and the absence of medication overuse and depressive symptoms are predictors of clinical response [22-32]. However, it is common experience to observe fluctuations in the clinical response to BT-A as to other preventive treatments. Assessing sustained response to BT-A is important to reliably quantify the benefit of the treatment on the patients' disability and quality of life. It is especially important nowadays, because alternative treatments are available for CM, namely monoclonal antibodies acting on the calcitonin gene-related peptide (CGRP) or its receptor [33, 34].

The present study aimed to assess proportion of patients who achieve sustained response to BT-A and to establish baseline headache characteristics which predict sustained response.

\section{Methods}

\section{Study population}

In this multicenter, prospective, open-label study, patients were consecutively enrolled from January 2015 to July 2018 in the tertiary headache centers of Modena and L'Aquila.

The following enrollment criteria were strictly followed: 1) a diagnosis of CM according to the International Classification of Headache Disorders, 2nd [35] and 3rd [36] edition; 2) clinical eligibility to BT-A treatment, i.e. prior failure of at least two oral preventive treatments; 3 ) consent to be followed up for at least 15 months as per duration of the PREEMPT protocol $[7,8,11]$.

Patients with medication overuse or concurrent oral preventive treatments were allowed to participate in the study, as well as patients who changed their oral preventive medications during treatment with BT-A.

\section{Study procedures}

At the baseline visit, we recorded the patients' demographic characteristics, including age, sex, and body mass index (BMI), by using a questionnaire. A daily headache diary was dispensed to patients to collect number of monthly headache days and days of acute medication use during the 3 months before the beginning of treatment with BT-A and throughout the follow-up. In addition, we collected the Migraine Disability Assessment Scale (MIDAS), the Headache Impact Test, 6thedition (HIT-6), and the Numerical Rating Scale (NRS) scores at baseline and every 3 months. Disability according to MIDAS score was 
categorized as 'no/ little' (score 0-5), 'mild' (score 6.10), and moderate/ severe' (score $\geq 11$ ); headache impact according to HIT-6 score was categorized as 'no/ little' (score 36-49), 'moderate' (score 50-54) and 'substantial-severe' (scores 55-78).

Each patient started BT-A treatment with a 155-unit 'fixed-dose, fixed-site' protocol, with the possibility of increasing the dose up to 195 units according to a 'follow-the-pain' strategy $[7,8]$. BT-A treatment cycles were planned to be repeated every 3 months. The study duration was of 15 months, equivalent to 5 treatment cycles plus 3 additional months of follow-up to evaluate the effect of the $5^{\text {th }}$ cycle. Each patient was encouraged to continue BT-A for at least 5 treatment cycles unless there was a treatment failure or any serious adverse event. Treatment failure was assessed after 3 treatment cycles ( 9 months) and was defined as a $<30 \%$ of reduction in headache days from baseline. All patients, even those who stopped treatment, were asked to fill in their diaries and questionnaires for the 15-month duration of the study follow-up.

\section{Definition of responders}

'Anytime responders' were defined as those patients who achieved a $\geq 50 \%$ reduction in headache days during any three-month treatment cycle compared with the three months prior to initiation of BT-A treatment; this definition is in line with commonly accepted criteria $[12,37,38]$.

'Sustained responders' were defined as those patients achieving a $\geq 50 \%$ reduction in headache days within the third treatment cycle and maintaining the response until the end of follow-up.

'Non-responders' were defined as patients who never achieved $a \geq 50 \%$ reduction in headache days during the follow-up.

Patients discontinuing BT-A treatment because of adverse events, ineffectiveness, or lack of adherence were considered as non-responders. For patients discontinuing treatment because of substantial clinical benefit, to address response status we considered the headache diaries and classified patients as above reported.

\section{Ethical aspects}

The study was approved by the local ethics committees of both participating centers (protocol number 334/2015 for Modena and 0203392/16 for L'Aquila). Each patient signed an informed consent before enrolment.

\section{Statistical analysis}

Categorical variables were reported as numbers and proportions while continuous variables were reported as mean \pm standard deviation or median with interquartile range (IQR) as appropriate. Data from all patients, including those who discontinued treatment, were included in the analyses. Demographic and headache characteristics were compared between responders and non-responders using the chi-squared test for categorical variables and the Mann-Whitney $U$ test for continuous variables. We did not pre-specify a sample size as it was based on available data. Statistical calculations were made using SPSS software, version 20. Statistical significance was set at $\mathrm{P}<0.05$.

\section{Results}

During the study period, 115 consecutive patients were treated with BT-A and provided consent to be followed up for 15 months. Among them, 87 (75.7\%) completed 5 BT-A treatment cycles; 9 (7.8\%) refused to continue BT-A after the third or fourth treatment cycle for clinical benefit (all had $>75 \%$ reduction in monthly headache days); 19 additional patients stopped BT-A because of treatment failure (6; 5.2\%), adverse events (2 with allergic reaction; $1.7 \%)$, or lack of adherence $(11 ; 9.6 \%)$, (Figure 1). All patients discontinuing treatment filled out diaries and questionnaires until the end of the study; no other patient was lost to follow-up. Patients who stopped BT-A for clinical benefit did not restart BT-A by the end of the study, nor started any other preventive treatment.

The baseline characteristics of the included patients are reported in Table 1. Most patients (84.3\%) were women, while the median age was 50 years (interquartile range [IQR] 44.5-54). Eighty-nine (77.4\%) patients had medication overuse and 61 (53.0\%) were on concurrent preventive treatments. The median migraine duration was 30 years, while the median CM duration was 62.5 months.

Headache days and medication days both decreased from a median of 30 (IQR 25-30) at baseline to 15 (IQR 7-25; P<0.001) (Table 2). The median headache intensity significantly decreased from 8 (IQR 7-9) to 5 (IQR 4-7; P<0.001). The patients' quality of life also improved, as suggested by the MIDAS score decrease from 87.5 (IQR 42.5-123.5) to 12 (IQR 3.5-51.5; P<0.001) and by the HIT-6 score decrease from 65 (IQR 60-69) to 62 (IQR 56-65; P<0.001).

The proportion of responders per cycle of treatment ranged from $18.3 \%$ to $41.7 \%$ over the study period (Figure 2 ). At the end of follow-up, 66 patients (57.4\%) patients were classified as anytime responders and the remaining 49 patients (42.6\%) were classified as non-responders. Fifty-one (44.3\%) patients achieved response to treatment within the third cycle; 33 (64.7\%) of them were classified as sustained responders while 18 (35.3\%) had fluctuations in treatment responses over the following cycles (Figure 3).

Figure 4 shows the clinical data stratified according to response status. Not only responders, but also non-responders had a significant decrease in the number of headache days and in headache intensity as compared to baseline. The disability (MIDAS) and impact (HIT-6) of headache improved numerically but not significantly after treatment in anytime and sustained responders (Figure 4). 
Sustained responders had a lower CM duration (31 vs 49 months; $\mathrm{P}=0.030$ ) and a lower median number of monthly headache days at baseline (25 vs $30 ; \mathrm{P}=$ 0.013) compared with non-responders (Table 3 ) while the baseline headache characteristics were similar in the two groups.

At the end of follow-up, 40 of the 115 included patients $(34.8 \%)$ had mild adverse events; the most common were local tension $(n=14 ; 12.2 \%)$, local pain $(n=$ $12 ; 10.4 \%)$, and muscle weakness or atrophy $(n=11 ; 9.6 \%)$.

\section{Discussion}

Migraine frequency and intensity, as well as response to treatments, undergo fluctuations as a response to internal and external triggering factors; the fluctuation between satisfactory and unsatisfactory responses to treatment might be frustrating for patients with $\mathrm{CM}$. A way to improve the management of patients with migraine is to evaluate not only the response to treatments at a given time point, but also sustained benefit over time. To our knowledge, our study is the first to address the concept of 'sustained response' to BT-A.

We found that more than half of patients had a $\geq 50 \%$ reduction in headache days from baseline after at least one cycle of BT-A treatment and that about two thirds of patients who achieved $a \geq 50 \%$ reduction in headache days within the third treatment cycle had a sustained response to BT-A. Our results should be read in the light of a difficult-to-treat study population, who had a high mean age and long history of migraine and of $\mathrm{CM}$. The proportion of patients with sustained response to BT-A treatment would likely be higher in less difficult-to-treat populations.

In our real-life setting, patients who had higher likelihood of sustained response were those with a shorter CM duration and lower burden of headache days. No other studies have evaluated predictors of sustained response and we can compare our findings only with those studies who have evaluated anytime response [22-32] (Table 4). Anyhow, our data suggest that some factors which predicted short-term response, including short CM duration, are predictors of sustained response $[29,31$ ] (Table 4). The comparable studies assessing the response to BT-A had heterogeneous treatment protocols, follow-up durations, and patient populations (Table 4). Three studies found that shorter migraine duration predicted a favorable response to BT-A [22, 29, 31], in line with our finding regarding CM duration. Notably, a favorable response to BT-A was not predicted by the overall duration of migraine, but rather by the duration of its chronic stage. Hence, the detection of migraine chronification is crucial to provide proper access to specialist care and the most effective options for CM treatment as early as possible. Other studies found that ocular or imploding headache predicted response to BT-A [23, 25, 26, 28], while in our study the pain location did not influence BT-A response. A further study found that medication overuse predicted unfavorable response to BT-A [32], which contrasts with our findings. The optimal management of CM associated with medication overuse is in fact controversial. Medication overuse is not a contraindication to BT-A treatment for $\mathrm{CM}$ and does not preclude its effectiveness [38, 40]. However, detoxication prior to BT-A initiation may per se determine reversion of CM and may improve the efficacy [41]. In our study population, detoxication prior to BT-A initiation was not mandatory; however, we cannot exclude that an extensive use of detoxication might increase the proportion of anytime and sustained responders.

The present study has several strengths. The study sample included patients with CM from two tertiary headache centers with experienced personnel. Besides, patients received a homogeneous treatment protocol whose response was assessed using standardized criteria. However, the present study is limited by the lack of assessment of migraine comorbidities, especially the psychiatric ones, which negatively affect the course of migraine [42] and might have a negative impact also on BT-A treatment [32]. Data on psychological treatments, including behavioral therapy [43], which might have benefited some patients were not collected in this study, such as the effect of concurrent oral preventive treatments on the response to BT-A treatment, mainly because the low number of patients in each treatment category. Besides, the change of oral preventive treatments during treatment with BT-A in some patients might have limited the homogeneity of the study population, in which baseline characteristics were the only considered. Prior response to acute medications and especially triptans was not explored, such as the information regarding the imploding or exploding nature of headache, thus limiting the comparability of the present study data with those of other studies [23, 25]. We chose a 15 -month follow-up to align with the 5 treatment cycles of the PREEMPT protocol; however, longer follow-up periods are needed to assess the possible long-term benefits of BT-A in sustained responders. Lastly, we chose a cutoff of $\geq 50 \%$ reduction in headache days to identify responders; a relevant proportion of patients might have experienced a clinical benefit from BT-A treatment even if not fulfilling the criteria to be defined as a 'responder' in our study (Figure 2). Previous data suggest that even a $\geq 30 \%$ reduction in headache days might be considered relevant to patients [12], while such a reduction identified patients as 'non-responders' according to our study criteria. Further studies are needed to find a better definition of 'response' to BT-A treatment, which takes into account the patients' quality of life.

\section{Conclusion}

According to our data, about two thirds of patients who achieve a clinically relevant response to BT-A within the third cycle of treatment maintain the response over time. More recent onset of $\mathrm{CM}$ and more headache-free days at baseline are associated with sustained response. Therefore, we suggest not to delay preventive treatment of CM with BT-A, in order to increase the likelihood of sustained clinical response.

\section{List Of Abbreviation}

BMI: body mass index

BT-A: onabotulinumtoxin A

CGRP: calcitonin gene-related peptide

Cl: confidence interval

CM: chronic migraine 
HIT-6: Headache Impact Test, $6^{\text {th }}$ Edition

IQR: interquartile range

MIDAS: Migraine Impact and Disability Assessment Scale

NRS: Numerical Rating Scale

PREEMPT: Phase 3 Research Evaluating Migraine Prophylaxis Therapy

\section{Declarations}

Ethics approval and consent to participate: the study was approved by the Internal Review Board of the University of L'Aquila and Modena (Italy) and patients gave written informed consent according to the Declaration of Helsinki.

Consent for publication: not applicable.

Availability of data and materials: anonymized data operated or analyzed during this study are available from the Authors upon reasonable request.

Competing interests: RO has received sponsorship to attend meetings from Novartis and Teva; SG participated in advisory boards for Allergan and Teva and in clinical trials for Allergan, Novartis, and Teva; SS had a financial relationship (lecturer or member of advisory board) with Abbott, Allergan, Novartis, Teva, and Eli Lilly; all the other Authors declare no competing interests.

Funding: the publication fee for the present paper was unconditionally granted by Allergan.

Authors' contributions: RO participated in data interpretation, performed the statistical analyses, and drafted the initial manuscript. SG and SS conceived the study, participated in data collection and interpretation, and drafted the manuscript. CB, IF, and LE performed data collection, participated in data interpretation, and revised the manuscript for intellectual content. CM and FP revised the manuscript for intellectual content.

Acknowledgements: The Authors wish to thank all the study patients for their kind cooperation.

\section{References}

[1]Headache Classification Committee of the International Headache Society (IHS) The International Classification of Headache Disorders, 3rd edition. Cephalalgia. 2018;38 1:1-211.

[2]Chalmer MA, Hansen TF, Lebedeva ER, Dodick DW, Lipton RB, Olesen J. Proposed new diagnostic criteria for chronic migraine. Cephalalgia. 2019:333102419877171.

[3]Natoli JL, Manack A, Dean B, Butler Q, Turkel CC, Stovner L, et al. Global prevalence of chronic migraine: a systematic review. Cephalalgia. 2010;30 5:599609.

[4]Manack AN, Buse DC, Lipton RB. Chronic migraine: epidemiology and disease burden. Curr Pain Headache Rep. 2011;15 1:70-78.

[5]Teixeira AL, Costa EA, da Silva AA, dos Santos IA, Gómez RS, Kummer A, et al. Psychiatric comorbidities of chronic migraine in community and tertiary care clinic samples. J Headache Pain. 2012;13 7:551-555.

[6]Bigal ME, Rapoport AM, Sheftell FD, Tepper SJ, Lipton RB. Transformed migraine and medication overuse in a tertiary headache centre-clinical characteristics and treatment outcomes. Cephalalgia. 2004;24 6:483-490.

[7]Aurora SK, Dodick DW, Turkel CC, DeGryse RE, Silberstein SD, Lipton RB, et al. OnabotulinumtoxinA for treatment of chronic migraine: results from the double-blind, randomized, placebo-controlled phase of the PREEMPT 1 trial. Cephalalgia. 2010;30 7:793-803.

[8]Diener HC, Dodick DW, Aurora SK, Turkel CC, DeGryse RE, Lipton RB, et al. OnabotulinumtoxinA for treatment of chronic migraine: results from the doubleblind, randomized, placebo-controlled phase of the PREEMPT 2 trial. Cephalalgia. 2010;30 7:804-814.

[9]Dodick DW, Turkel CC, DeGryse RE, Aurora SK, Silberstein SD, Lipton RB, et al. OnabotulinumtoxinA for treatment of chronic migraine: pooled results from the double-blind, randomized, placebo-controlled phases of the PREEMPT clinical program. Headache. 2010;50 6:921-936.

[10]Aurora SK, Winner P, Freeman MC, Spierings EL, Heiring JO, DeGryse RE, et al. OnabotulinumtoxinA for treatment of chronic migraine: pooled analyses of the 56-week PREEMPT clinical program. Headache. 2011;51 9:1358-1373.

[11]Aurora SK, Dodick DW, Diener HC, DeGryse RE, Turkel CC, Lipton RB, et al. OnabotulinumtoxinA for chronic migraine: efficacy, safety, and tolerability in patients who received all five treatment cycles in the PREEMPT clinical program. Acta Neurol Scand. 2014;129 1:61-70.

[12]Khalil M, Zafar HW, Quarshie V, Ahmed F. Prospective analysis of the use of OnabotulinumtoxinA (BOTOX) in the treatment of chronic migraine; real-life data in 254 patients from Hull, U. K. J Headache Pain. 2014;15:54.

Page 5/13 
[13]Cernuda-Morollón E, Ramón C, Larrosa D, Alvarez R, Riesco N, Pascual J. Long-term experience with onabotulinumtoxinA in the treatment of chronic migraine: What happens after one year? Cephalalgia. 2015;35 10:864-868.

[14]Pedraza MI, de la Cruz C, Ruiz M, López-Mesonero L, Martínez E, de Lera M, et al. OnabotulinumtoxinA treatment for chronic migraine: experience in 52 patients treated with the PREEMPT paradigm. Springerplus. 2015;4:176.

[15]Russo M, Manzoni GC, Taga A, Genovese A, Veronesi L, Pasquarella C, et al. The use of onabotulinum toxin A (Botox( $\left.\left({ }^{2}\right)\right)$ in the treatment of chronic migraine at the Parma Headache Centre: a prospective observational study. Neurol Sci. 2016;37 7:1127-1131.

[16]Aicua-Rapun I, Martínez-Velasco E, Rojo A, Hernando A, Ruiz M, Carreres A, et al. Real-life data in 115 chronic migraine patients treated with Onabotulinumtoxin A during more than one year. J Headache Pain. 2016;17 1:112.

[17]Kollewe K, Escher CM, Wulff DU, Fathi D, Paracka L, Mohammadi B, et al. Long-term treatment of chronic migraine with OnabotulinumtoxinA: efficacy, quality of life and tolerability in a real-life setting. J Neural Transm (Vienna). 2016;123 5:533-540.

[18]Blumenfeld AM, Stark RJ, Freeman MC, Orejudos A, Manack Adams A. Long-term study of the efficacy and safety of OnabotulinumtoxinA for the prevention of chronic migraine: COMPEL study. J Headache Pain. 2018;19 1:13.

[19]Ahmed F, Gaul C, García-Moncó JC, Sommer K, Martelletti P, Investigators RP. An open-label prospective study of the real-life use of onabotulinumtoxinA for the treatment of chronic migraine: the REPOSE study. J Headache Pain. 2019;20 1:26.

[20]Stark C, Stark R, Limberg N, Rodrigues J, Cordato D, Schwartz R, et al. Real-world effectiveness of onabotulinumtoxinA treatment for the prevention of headaches in adults with chronic migraine in Australia: a retrospective study. J Headache Pain. 2019;20 1:81.

[21]Alpuente A, Gallardo VJ, Torres-Ferrus M, Alvarez-Sabin J, Pozo-Rosich P. Early efficacy and late gain in chronic and high-frequency episodic migraine with onabotulinumtoxinA. Eur J Neurol. 2019; doi: 10.1111/ene.14028.

[22]Eross EJ, Gladstone JP, Lewis S, Rogers R, Dodick DW. Duration of migraine is a predictor for response to botulinum toxin type A. Headache. 2005;45 4:308-314.

[23]Jakubowski M, McAllister PJ, Bajwa ZH, Ward TN, Smith P, Burstein R. Exploding vs. imploding headache in migraine prophylaxis with Botulinum Toxin A. Pain. 2006;125 3:286-295.

[24]Mathew NT, Kailasam J, Meadors L. Predictors of response to botulinum toxin type A (BoNTA) in chronic daily headache. Headache. 2008;48 2:194-200.

[25]Burstein R, Dodick D, Silberstein S. Migraine prophylaxis with botulinum toxin A is associated with perception of headache. Toxicon. $2009 ; 54$ 5:624-627.

[26]Kim CC, Bogart MM, Wee SA, Burstein R, Arndt KA, Dover JS. Predicting migraine responsiveness to botulinum toxin type A injections. Arch Dermatol. 2010;146 2:159-163.

[27]Bumb A, Seifert B, Wetzel S, Agosti R. Patients profiling for Botox® (onabotulinum toxin A) treatment for migraine: a look at white matter lesions in the MRI as a potential marker. Springerplus. 2013;2:377.

[28]Lin KH, Chen SP, Fuh JL, Wang YF, Wang SJ. Efficacy, safety, and predictors of response to botulinum toxin type A in refractory chronic migraine: a retrospective study. J Chin Med Assoc. 2014;77 1:10-15.

[29]Lee MJ, Lee C, Choi H, Chung CS. Factors associated with favorable outcome in botulinum toxin A treatment for chronic migraine: A clinic-based prospective study. J Neurol Sci. 2016;363:51-54.

[30]Domínguez C, Vieites-Prado A, Pérez-Mato M, Sobrino T, Rodríguez-Osorio X, López A, et al. CGRP and PTX3 as Predictors of Efficacy of Onabotulinumtoxin Type A in Chronic Migraine: An Observational Study. Headache. 2018;58 1:78-87.

[31]Domínguez C, Pozo-Rosich P, Leira Y, Leira R. Unilateral pain and shorter duration of chronic migraine are significant predictors of response to onabotulinumtoxin A. Eur J Neurol. 2018;25 4:e48; doi: 10.1111/ene.13570.

[32]Schiano di Cola F, Caratozzolo S, Liberini P, Rao R, Padovani A. Response Predictors in Chronic Migraine: Medication Overuse and Depressive Symptoms Negatively Impact Onabotulinumtoxin-A Treatment. Front Neurol. 2019;10:678.

[33]Sacco S, Bendtsen L, Ashina M, Reuter U, Terwindt G, Mitsikostas DD, et al. European headache federation guideline on the use of monoclonal antibodies acting on the calcitonin gene related peptide or its receptor for migraine prevention. J Headache Pain. 2019;20 1:6.

[34]Tiseo C, Ornello R, Pistoia F, Sacco S. How to integrate monoclonal antibodies targeting the calcitonin gene-related peptide or its receptor in daily clinical practice. J Headache Pain. 2019;20 1:49.

[35]Olesen J, Steiner TJ. The International classification of headache disorders, 2nd edn (ICDH-II). J Neurol Neurosurg Psychiatry. $2004 ; 75$ 6:808-811.

[36] Headache Classification Committee of the International Headache Society (IHS). The International Classification of Headache Disorders, 3rd edition (beta version). Cephalalgia. 2013;33 9:629-808. 
[37]National Institute for Clinical Excellence (NICE): Botulinum toxin type A for the prevention of headaches in adults with chronic migraine. 2012.

[38]Bendtsen L, Sacco S, Ashina M, Mitsikostas D, Ahmed F, Pozo-Rosich P, et al. Guideline on the use of onabotulinumtoxinA in chronic migraine: a consensus statement from the European Headache Federation. J Headache Pain. 2018;19 1:91.

[39]Chow SC, Shao J, Wang H. Sample Size Calculations in Clinical Research. 2nd Edition edn: Chapman \& Hall; 2008.

[40]Herd CP, Tomlinson CL, Rick C, Scotton WJ, Edwards J, Ives NJ, et al. Cochrane systematic review and meta-analysis of botulinum toxin for the prevention of migraine. BMJ Open. 2019;9 7:e027953.

[41]Pijpers JA, Kies DA, Louter MA, van Zwet EW, Ferrari MD, Terwindt GM. Acute withdrawal and botulinum toxin A in chronic migraine with medication overuse: a double-blind randomized controlled trial. Brain. 2019;142 5:1203-1214.

[42]Dresler T, Caratozzolo S, Guldolf K, Huhn JI, Loiacono C, Niiberg-Pikksööt T, et al. Understanding the nature of psychiatric comorbidity in migraine: a systematic review focused on interactions and treatment implications. J Headache Pain. 2019;20 1:51.

[43]Pistoia F, Sacco S, Carolei A. Behavioral therapy for chronic migraine. Curr Pain Headache Rep. 2013;17 1:304.

\section{Table}

Table 1. Baseline characteristics of the study patients $(\mathrm{N}=115)$ 


\begin{tabular}{|c|c|}
\hline Female, n (\%) & $97(84.3)$ \\
\hline Age, median (IQR) & $50(44.5-54)$ \\
\hline \multicolumn{2}{|l|}{ Medical history, n (\%) } \\
\hline Smoking & $23(20.0)$ \\
\hline Alcohol abuse & $10(8.7)$ \\
\hline Family history of headaches & $78(67.8)$ \\
\hline Arterial hypertension & $29(25.2)$ \\
\hline BMI, median (IQR) & $23(20-25)$ \\
\hline \multicolumn{2}{|l|}{ Headache characteristics, n (\%) } \\
\hline Aura & $19(16.5)$ \\
\hline Allodynia & $38(33.0)$ \\
\hline \multicolumn{2}{|l|}{ Pain characteristics, n (\%) } \\
\hline Unilateral & $48(41.7)$ \\
\hline Throbbing & $74(64.3)$ \\
\hline Diffuse & $24(20.9)$ \\
\hline Frontal & $60(52.2)$ \\
\hline Temporal & $59(51.3)$ \\
\hline Ocular & $34(29.6)$ \\
\hline Occipital & $15(13.0)$ \\
\hline Parietal & $15(13.0)$ \\
\hline Vertex & $9(7.8)$ \\
\hline Medication overuse, n (\%) & $89(77.4)$ \\
\hline \multicolumn{2}{|l|}{ Preventive treatments in history, $\mathrm{n}(\%)$} \\
\hline Antidepressants & $82(71.3)$ \\
\hline Anticonvulsants & $69(60.0)$ \\
\hline Calcium antagonists & $42(36.5)$ \\
\hline Other & $8(7.0)$ \\
\hline Concurrent oral preventive treatments, $\mathrm{n}(\%)$ & $61(53.0)$ \\
\hline Migraine duration (years), median (IQR) & $30(22-39.5)$ \\
\hline Chronic migraine duration (months), median (IQR) & $62.5(24-144)$ \\
\hline
\end{tabular}

$\mathrm{BMI}$ indicates body mass index; IQR, interquartile range

Table 2. Change in study outcomes at 15 -month follow-up in the 115 included patients

\begin{tabular}{|lllc|}
\hline Outcome & $\begin{array}{l}\text { Pre-treatment } \\
\text { median (IQR) }\end{array}$ & Post-treatment median (IQR) & P value \\
\hline Headache days & $30(25-30)$ & $15(7-25)$ & $<0.001$ \\
Medication days & $30(25-30)$ & $15(7-25)$ & $<0.001$ \\
\hline MIDAS score & $87.5(42.5-123.5)$ & $12(3.5-51.5)$ & 0.001 \\
\hline HIT-6 score & $65(60-69)$ & $62(56-65)$ & $<0.001$ \\
\hline NRS score & $8(7-9)$ & $5(4-7)$ & $<0.001$ \\
\hline
\end{tabular}

HIT-6 indicates Headache Impact Test, $6^{\text {th }}$ edition; IQR, interquartile range; MIDAS, Migraine Impact and Disability Assessment Scale; NRS, Numerical Rating Scale. 
Table 3. Univariate comparison of the characteristics of responders vs non-responders to treatment with onabotulinumtoxin-A

\begin{tabular}{|c|c|c|c|c|c|}
\hline & $\begin{array}{l}\text { Non-responders } \\
(\mathrm{n}=49)\end{array}$ & $\begin{array}{l}\text { Anytime responders } \\
(n=66)\end{array}$ & $P$ value & $\begin{array}{l}\text { Sustained responders } \\
(n=33)\end{array}$ & $P$ value \\
\hline Age, median (IQR) & $50(42-55)$ & $49(44-54)$ & 0.627 & $49(45-53)$ & 0.491 \\
\hline Female sex, n (\%) & $43(87.8)$ & $54(81.8)$ & 0.386 & $28(84.8)$ & 0.705 \\
\hline Migraine years, median (IQR) & $3121.5-40)$ & $30(22-40)$ & 0.913 & $25(20-34)$ & 0.155 \\
\hline Chronic migraine duration (months), median (IQR) & $65(25-120)$ & $49(21-126)$ & 0.732 & $31(15.5-60)$ & 0.030 \\
\hline Monthly headache days, median (IQR) & $30(30-30)$ & $30(24-30)$ & 0.176 & $25(21.5-30)$ & 0.013 \\
\hline Medication overuse, $\mathrm{n}(\%)$ & $37(82.2)$ & $52(78.8)$ & 0.656 & $22(66.7)$ & 0.114 \\
\hline Aura, n (\%) & $11(23.4)$ & $8(12.1)$ & 0.114 & $3(9.1)$ & $0.137 *$ \\
\hline Allodynia, n (\%) & $18(45.0)$ & $20(33.9)$ & 0.265 & $13(41.9)$ & 0.796 \\
\hline Unilateral headache, n (\%) & $18(38.3)$ & $30(45.5)$ & 0.449 & $15(45.5)$ & 0.522 \\
\hline Throbbing headache, n (\%) & $30(63.8)$ & $44(66.7)$ & 0.755 & $21(63.6)$ & 0.986 \\
\hline Diffuse headache, n (\%) & $11(23.4)$ & $13(20.0)$ & 0.665 & $5(15.2)$ & $0.409 *$ \\
\hline Frontal headache, n (\%) & $23(48.9)$ & $37(56.1)$ & 0.454 & $22(66.7)$ & 0.116 \\
\hline Temporal headache, n (\%) & $26(55.3)$ & $33(50.0)$ & 0.577 & $17(51.5)$ & 0.737 \\
\hline Orbital headache, n (\%) & $13(27.7)$ & $21(31.8)$ & 0.635 & $7(21.2)$ & 0.612 \\
\hline Occipital headache, n (\%) & $7(14.9)$ & $8(12.1)$ & 0.669 & $4(12.1)$ & $0.999 *$ \\
\hline Parietal headache, n (\%) & $9(19.1)$ & $6(9.1)$ & 0.120 & $3(9.1)$ & $0.341^{*}$ \\
\hline Vertex headache, n (\%) & $6(12.8)$ & $3(4.5)$ & 0.112 & $2(6.1)$ & $0.459 *$ \\
\hline
\end{tabular}

*Fisher'e exact test

Table 4. Characteristics of real-life studies of onabotulinumtoxin A for the treatment of migraine assessing predictors of treatment response 


\begin{tabular}{|c|c|c|c|c|c|c|c|c|c|}
\hline Study & Country & $\mathrm{N}$ & $\%$ women & $\begin{array}{l}\text { Years of age, } \\
\text { mean } \pm S D \\
\text { (range) }\end{array}$ & $\% \mathrm{CM}$ & $\begin{array}{l}\text { Years from CM } \\
\text { onset, mean } \pm S D \\
\text { (range) }\end{array}$ & $\begin{array}{l}\% \text { medication } \\
\text { overuse }\end{array}$ & $\begin{array}{l}\text { BT-A } \\
\text { dose } \\
\text { range } \\
(\mathrm{U})\end{array}$ & $\begin{array}{l}\text { Max } \\
\text { follow-uf } \\
\text { (months) }\end{array}$ \\
\hline $\begin{array}{l}\text { Eross, } \\
2005 \text { [22] }\end{array}$ & USA & 61 & 90.0 & $46.5(15-81)$ & 77 & NR & NR & $\begin{array}{l}25- \\
100\end{array}$ & 4 \\
\hline $\begin{array}{l}\text { Jakubowski, } \\
2006 \text { [23] }\end{array}$ & USA & 27 & 92.6 & $41.9 \pm 1.7$ & NR & NR & NR & 100 & 12 \\
\hline $\begin{array}{l}\text { Mathew, } \\
2008 \text { [24] }\end{array}$ & USA & 71 & 90.1 & $(19-69)$ & 100.0 & NR & NR & 100 & 7 \\
\hline $\begin{array}{l}\text { Burstein, } \\
2009 \text { [25] }\end{array}$ & USA & 82 & 84.1 & $50.9 \pm 1.2(21-75)$ & 67.0 & NR & NR & NR & NR \\
\hline $\begin{array}{l}\text { Kim, } \\
2010 \text { [26] }\end{array}$ & USA & 18 & 94.4 & $50.9(26-80)$ & NR & NR & NR & $\begin{array}{l}25- \\
300\end{array}$ & 3 \\
\hline $\begin{array}{l}\text { Bumb } \\
2013 \text { [27] }\end{array}$ & Switzerland & 111 & $\begin{array}{l}85 \text { (responders) } \\
77 \\
\text { (nonresponders) }\end{array}$ & $\begin{array}{l}47 \text { (responders) } \\
52 \\
\text { (nonresponders) }\end{array}$ & $\begin{array}{l}66.0 \\
\text { (responders) } \\
62.5 \\
\text { (nonresponders) }\end{array}$ & NR & NR & 100 & NR \\
\hline $\begin{array}{l}\text { Lin, } \\
2014 \text { [28] }\end{array}$ & Taiwan & 94 & 84.0 & $\begin{array}{l}47.6 \pm 13.6(20- \\
85)\end{array}$ & 100.0 & $8.1 \pm 8.3(1-40)$ & 19.1 & $\begin{array}{l}75- \\
155\end{array}$ & 3 \\
\hline $\begin{array}{l}\text { Lee, } \\
2016 \text { [29] }\end{array}$ & $\begin{array}{l}\text { South } \\
\text { Korea }\end{array}$ & 70 & $\begin{array}{l}85.7 \\
\text { (responders) } \\
85.7 \\
\text { (nonresponders) }\end{array}$ & $\begin{array}{l}48.0 \pm 13.6 \\
\text { (responders) } \\
46.9 \pm 10.2 \\
\text { (nonresponders) }\end{array}$ & 100.0 & $\begin{array}{l}\text { Median } 10 \text { (IQR } \\
5-17) \\
\text { (responders) } \\
\text { Median } 15 \text { (IQR } \\
\text { 10-25) } \\
\text { (nonresponders) }\end{array}$ & $\begin{array}{l}47.6 \\
\text { (responders) } \\
50.0 \\
\text { (nonresponders) }\end{array}$ & 155 & 1 \\
\hline $\begin{array}{l}\text { Dominguez, } \\
2017 \text { [30] }\end{array}$ & Spain & 62 & $\begin{array}{l}97.9 \\
\text { (responders) } \\
93.3 \\
\text { (nonresponders) }\end{array}$ & $\begin{array}{l}51.6 \pm 9.1 \\
\text { (responders) } \\
39.4 \pm 12.0 \\
\text { (nonresponders) }\end{array}$ & 100.0 & $\begin{array}{l}1.5 \pm 1.0 \\
\text { (responders) } \\
1.8 \pm 1.3 \\
\text { (nonresponders) }\end{array}$ & NR & 155 & 6 \\
\hline $\begin{array}{l}\text { Dominguez, } \\
2018 \text { [31] }\end{array}$ & Spain & 725 & 85.8 & $46.8 \pm 12.0$ & 100.0 & $1.7 \pm 1.6$ & 58.2 & NR & 12 \\
\hline $\begin{array}{l}\text { Schiano di } \\
\text { Cola, } \\
2019 \text { [32] }\end{array}$ & Italy & 84 & 72.6 & $48.0 \pm 9.7$ & 100.0 & $10.1 \pm 6.6$ & 65.5 & $\begin{array}{l}155- \\
175\end{array}$ & 12 \\
\hline
\end{tabular}




\section{Figures}

\section{Figure 1 not included in this version.}

Figure 1

Flowchart of patient inclusion. (not included in this version)

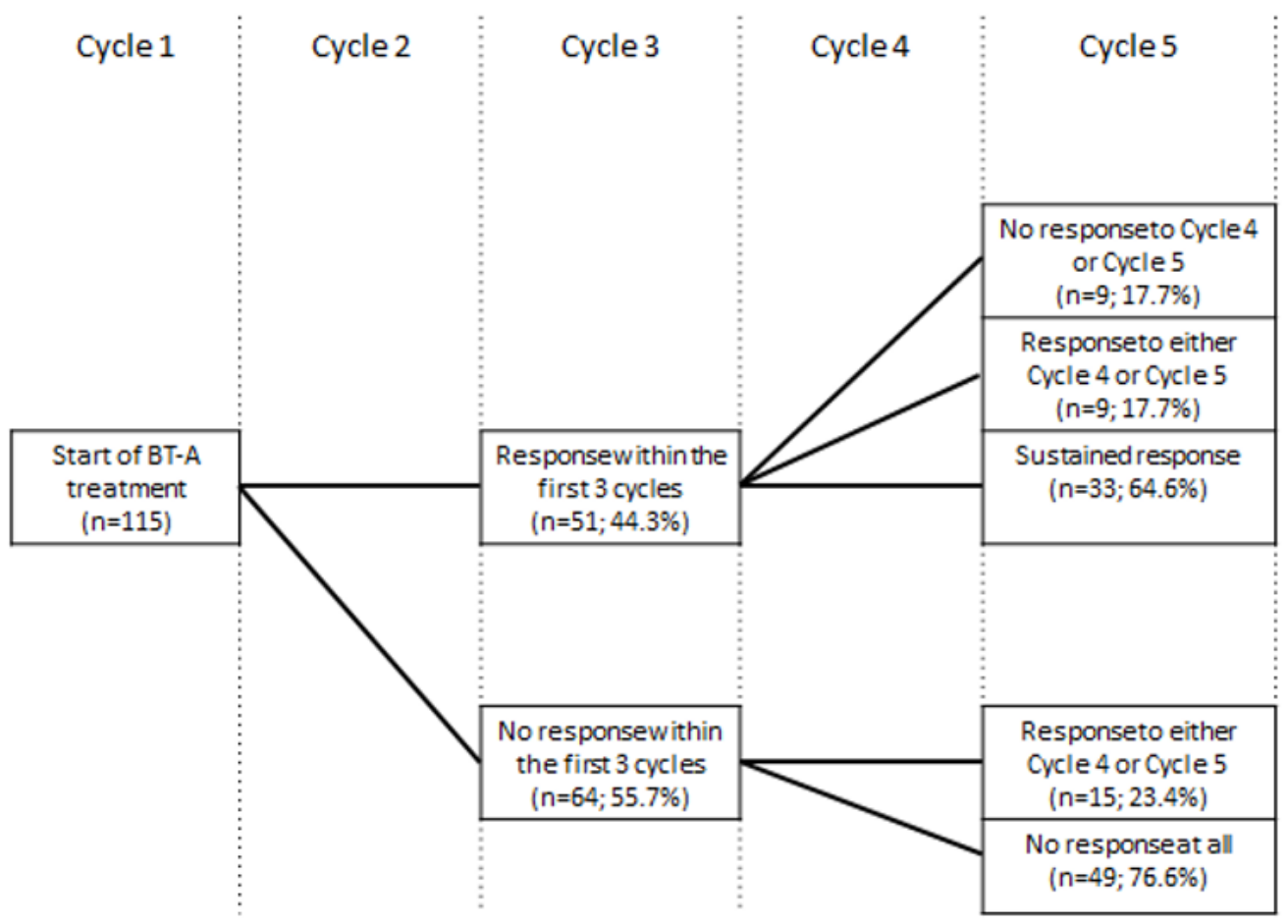

Figure 2

Proportion and course of response to treatment with onabotulinumtoxin A. 


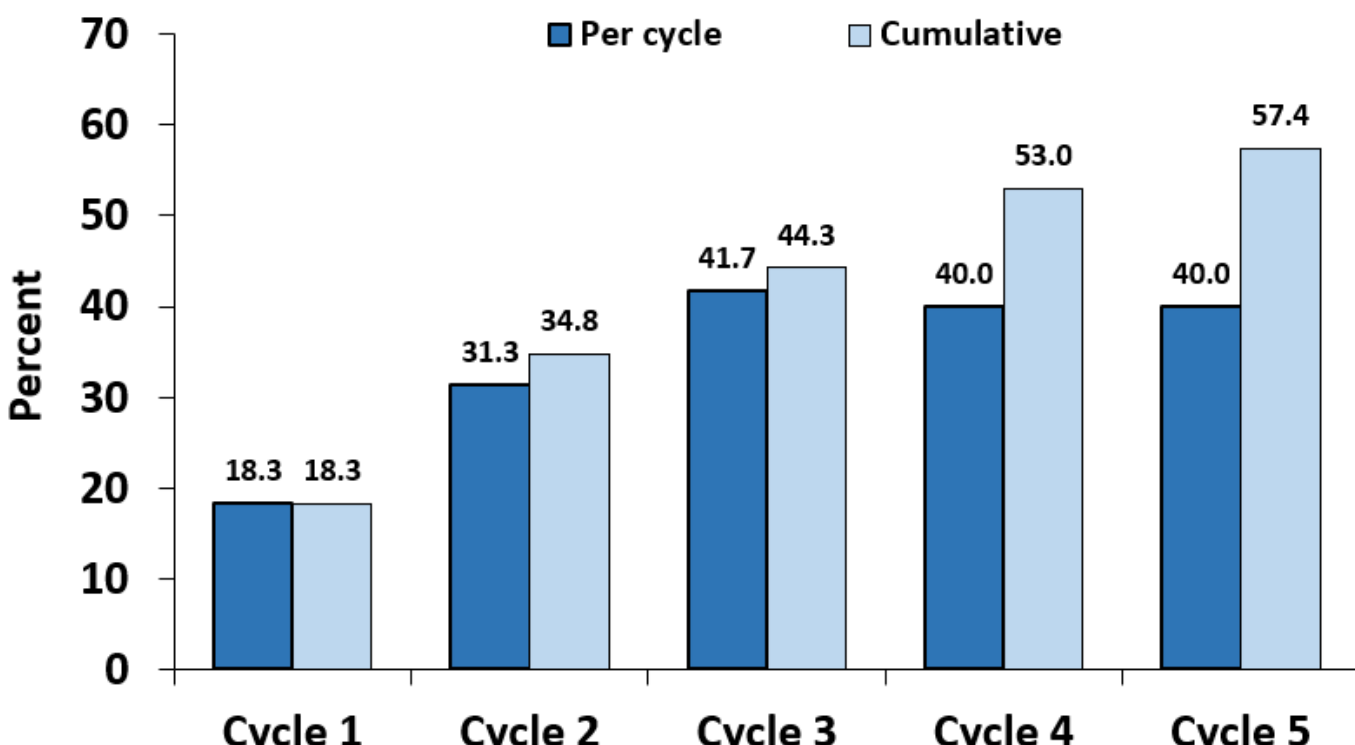

Figure 3

Proportion of patients with $\geq 50 \%$ reduction in headache days during each three-month treatment cycle compared with the three months prior to initiation of treatment with onabotulinumtoxin $\mathrm{A}$.
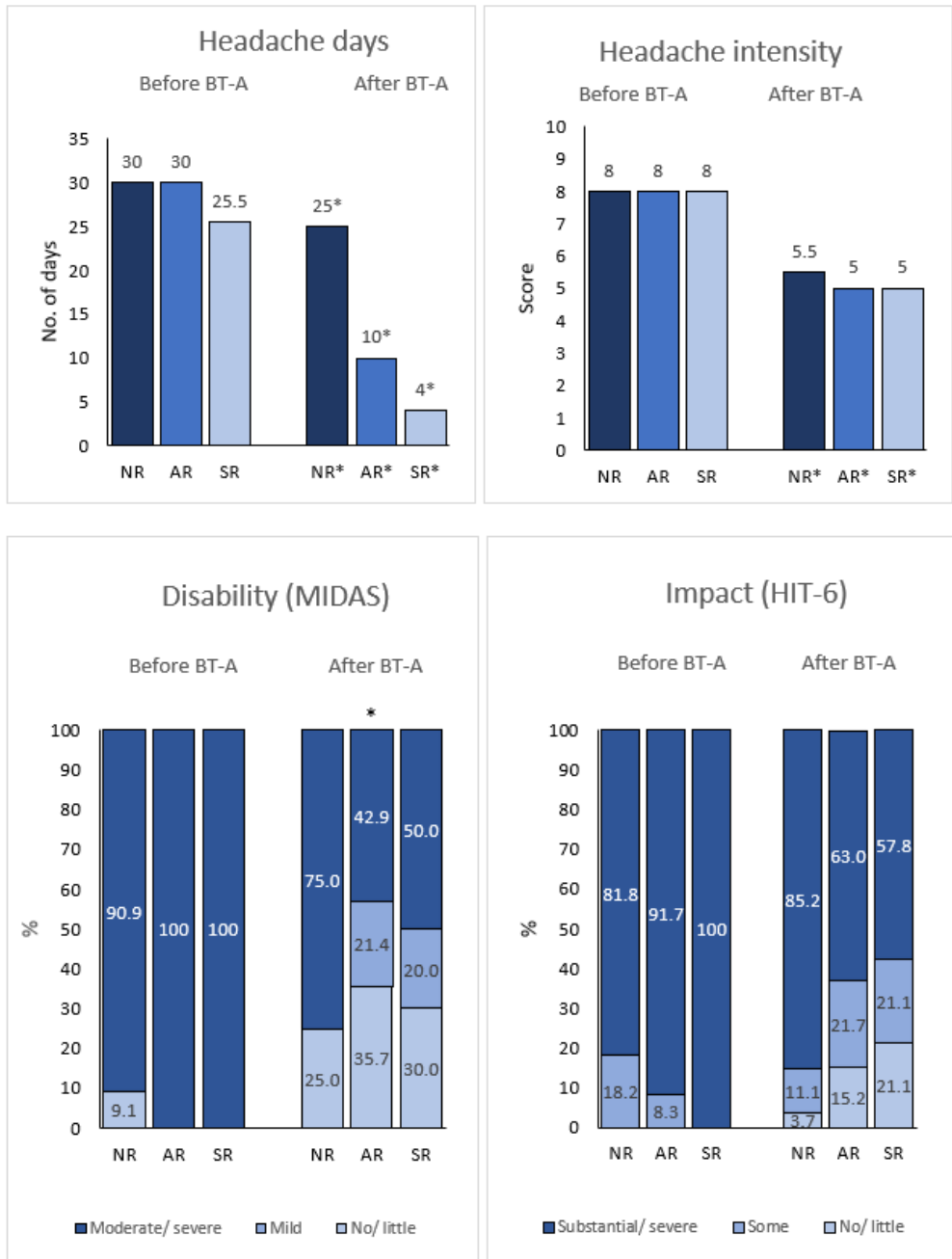
Median headache days and intensity and patients distribution according to MIDAS and HIT-6 scores during the 3 months before onabotulinumtoxin A initiation and during the final 3 months of follow-up. Results are stratified by response status. The asterisk $(*)$ identifies significant changes compared with pre-treatment. NR indicates non-responders; AR, anytime responders; SR, sustained responders. 